\title{
Hypoxia modulates cell migration and proliferation in placenta-derived mesenchymal stem cells
}

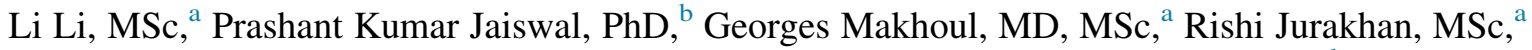 \\ Kaviyanka Selvasandran, MSc, ${ }^{a}$ Khalid Ridwan, MD, MSc, ${ }^{a}$ and Renzo Cecere, $\mathrm{MD}^{\mathrm{a}, \mathrm{b}}$
}

\begin{abstract}
Objectives: For more than a decade, stem cells isolated from different tissues have been evaluated in cell therapy. Among them, the human bone marrowderived mesenchymal stem cells (hBM-MSCs) were investigated extensively in the treatment of myocardial infarction. Recently, the human placenta-derived mesenchymal stem cells (hPD-MSCs), which are readily available from a biological waste, appear to be a viable alternative to hBM-MSCs.
\end{abstract}

Methods: $\mathrm{C}-\mathrm{X}-\mathrm{C}$ chemokine receptor type 4 (CXCR4) gene expression and localization were detected and validated in hPD-MSCs and hBM-MSCs via polymerase chain reaction and immunofluorescence. Subsequently, cell culture conditions for CXCR4 expression were optimized in stromal-derived factor-1 alpha (SDF1$\alpha$ ), glucose, and cobalt chloride $\left(\mathrm{CoCl}_{2}\right)$ by the use of cell viability, proliferation, and migration assays. To elucidate the cell signaling pathway, protein expression of CXCR4, hypoxia-inducible factor- $1 \alpha$, interleukin-6, Akt, and extracellular signal-regulated kinase were analyzed by Western blot. CXCR4-positive cells were sorted and analyzed by florescence-activated cell sorting.

Results: CXCR4 was expressed on both hPD-MSCs and hBM-MSCs at the basal level. HPD-MSCs were shown to have a greater sensitivity to SDF- $1 \alpha$-dependent cell migration compared with hBM-MSCs. In addition, CXCR4 expression was significantly greater in both hPD-MSCs and hBM-MSCs with SDF- $1 \alpha$ or $\mathrm{CoCl}_{2}$-induced hypoxia treatment. However, CXCR4 ${ }^{+}$hPD-MSCs population increased by 10 -fold in $\mathrm{CoCl}_{2}$-induced hypoxia. In contrast, only a 2 -fold increase was observed in the $\mathrm{CXCR} 4^{+} \mathrm{hBM}-\mathrm{MSC}$ population in similar conditions. After $\mathrm{CoCl}_{2}$-induced hypoxia, the CXCR4/mitogen-activated protein kinase kinase/extracellular signal-regulated kinase signaling pathway was activated prominently in hPD-MSCs, whereas in hBM-MSCs, the CXCR4/ phosphatidylinositol 3-kinase/Akt pathway was triggered.

Conclusions: Our current results suggest that hPD-MSCs could represent a viable and effective alternative to hBM-MSCs for translational studies in cardiocellular repair. (J Thorac Cardiovasc Surg 2017;154:543-52)

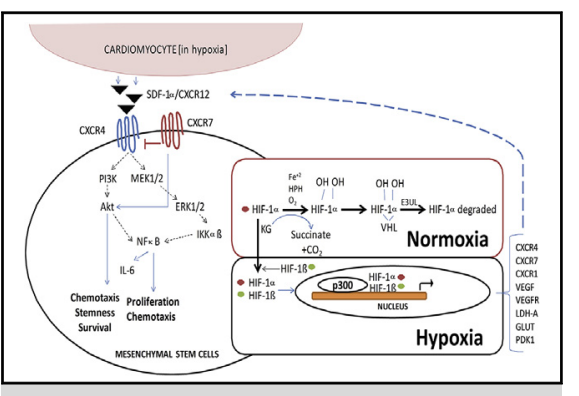

Human placenta-derived mesenchymal stem cells have a greater sensitivity to SDF- $1 \alpha$-dependent cell migration than human bone marrow-derived mesenchymal stem cells.

\section{Central Message}

Greater sensitivity of human placenta-derived mesenchymal stem cells to stromal-derived factor-1 alpha-dependent cell migration compared with human bone marrow-derived mesenchymal stem cells indicates that they could be used as alternative to human bone marrow-derived mesenchymal stem cells for experimental studies.

\section{Perspective}

Our data provide new insights into the comparative molecular mechanisms that regulate mesenchymal stem cell (MSC) migration derived from different tissue sources (bone and placenta). Human placenta-derived MSCs were shown to have greater sensitivity to stromal-derived factor-1 alpha-dependent cell migration compared with human bone marrow-derived MSCs. These findings may have experimental implications for the use of human placenta-derived MSCs as an alternative to human bone marrow-derived MSCs.

See Editorial Commentary page 553.

See Editorial page 541.
From the ${ }^{\mathrm{a} D i v i s i o n}$ of Experimental Surgery, McGill University; and ${ }^{\mathrm{b}}$ Division of Cardiac Surgery, McGill University Health Centre, Montreal, Quebec, Canada.

Supported by a research grant from the Richard \& Edith Strauss Canada Foundation, Montreal, Canada.

Read at the 96th Annual Meeting of The American Association for Thoracic Surgery, May 14-18, 2016, Baltimore, Maryland.

Received for publication Aug 29, 2016; revisions received Feb 28, 2017; accepted for publication March 13, 2017; available ahead of print May 16, 2017.
Address for reprints: Renzo Cecere, MD, Glen Campus - The Royal Victoria Hospital, McGill University Health Center, 1001 Decarie Blvd, Block C, C07.1284, Montreal, Quebec H4A 3J1, Canada (E-mail: renzo.cecere@muhc.mcgill.ca). $0022-5223 / \$ 36.00$

Copyright (C) 2017 by The American Association for Thoracic Surgery http://dx.doi.org/10.1016/j.jtcvs.2017.03.141 


\begin{tabular}{|c|c|}
\hline \\
\hline \multicolumn{2}{|c|}{$\mathrm{CoCl}_{2}=$ cobalt chloride } \\
\hline CXCR4 & $=\mathrm{C}-\mathrm{X}-\mathrm{C}$ chemokine receptor type 4 \\
\hline DMEM & $\begin{aligned} &= \text { Dulbecco's modified Eagle's } \\
& \text { medium }\end{aligned}$ \\
\hline ERK & $=$ extracellular signal-regulated kinase \\
\hline FACS & $=$ fluorescence-activated cell sorting \\
\hline \multicolumn{2}{|c|}{$\begin{aligned} \mathrm{hBM}-\mathrm{MSCs}= & \text { human bone marrow-derived } \\
& \text { mesenchymal stem cells }\end{aligned}$} \\
\hline hPD-MS & $\begin{aligned}= & \text { human placenta-derived } \\
& \text { mesenchymal stem cells }\end{aligned}$ \\
\hline IL-6 & $=$ interleukin -6 \\
\hline MEK & $\begin{aligned} &= \text { mitogen-activated protein kinase } \\
& \text { kinase }\end{aligned}$ \\
\hline MI & $=$ mycocardial infarction \\
\hline MSC & $=$ mesenchymal stem cell \\
\hline $\mathrm{NF} \kappa \mathrm{B}$ & $=$ nuclear factor $\kappa \beta$ \\
\hline RT-PCR & $\begin{aligned}= & \text { reverse transcription polymerase } \\
& \text { chain reaction }\end{aligned}$ \\
\hline SDF- $1 \alpha$ & $=$ stromal-derived factor- 1 alpha \\
\hline
\end{tabular}

Scanning this QR code will take you to a supplemental video, tables, and figures. To view the AATS 2016 Webcast, see the URL next to the webcast thumbnail.
Stem cells isolated from the bone marrow are the most commonly accessed source. These human bone marrowderived mesenchymal stem cells (hBM-MSCs) have been studied extensively for the treatment of MI. ${ }^{9}$ Interestingly, MSCs additionally were reported in other tissues, such as the umbilical cord, the adipose tissue, the liver, and the term placenta. With its easy accessibility, the human placenta generally is discarded after birth, and the stem cells can be readily isolated, avoiding any ethical concerns. ${ }^{10}$ Moreover, few studies have demonstrated that the human placenta-derived mesenchymal stem cells (hPD-MSCs) could be a suitable alternative to hBM-MSCs in cardiac repair. ${ }^{11}$

After MI, the stromal-derived factor-1 alpha (SDF-1 $\alpha$ ) and its chemokine receptor $\mathrm{C}-\mathrm{X}-\mathrm{C}$ chemokine receptor type 4 (CXCR4) is a critical axis in regulating cell migration, homing, and engraftment. It has been shown that SDF- $1 \alpha$ is expressed and secreted by cardiomyocytes of the ischemic heart, whereas CXCR4 is expressed on the cell surface of MSCs. ${ }^{12}$ The interaction between these 2 components elicits a migratory response of the MSCs up the SDF- $1 \alpha$ gradient, and this mechanism assists these stem cells in reaching the site of infarction.

The CXCR4/SDF1- $\alpha$ axis triggers a downstream signaling cascade tightly regulated by various pathways, such as the phosphatidylinositol 3-kinase (PI3K)/Akt and mitogen-activated protein kinase pathways. ${ }^{13-15}$ In the $\mathrm{PI} 3 \mathrm{~K} /$ Akt pathway, Akt is responsible for phosphorylating many cytosolic and nuclear molecules involved in cell survival, cell-cycle progression, and cell growth. ${ }^{16}$ In the mitogen-activated protein kinase pathway, nuclear factor $\kappa \beta(\mathrm{NF} \kappa \mathrm{B})$ and other transcription factors relevant to cardiac repair are activated. ${ }^{2,17}$

Despite their cardiac repairing properties and their paracrine effects, the hPD-MSCs have not been well explored as the hBM-MSCs, in particular at the SDF- $1 \alpha /$ CXCR4 axis. Thus, this study aimed to assess the appropriateness of hPD-MSCs as a novel alternative cell source for cardiac repair.

\section{MATERIALS AND METHODS \\ Cell Culture and Treatment}

The hPD-MSCs (kindly donated by Dr Huang Yen laboratory in Taiwan $^{18}$ ) and hBM-MSCs (Lonza, Basel, Switzerland) were cultured in Dulbecco's modified Eagle's medium (DMEM) supplemented with $10 \%$ fetal bovine serum. Cells at confluence were harvested and seeded onto 10-cm cell culture dishes (Nest Scientific USA, Rahway, NJ). Cells were treated under different conditions: SDF-1 $\alpha$ (PeproTech, Rocky Hill, NJ), glucose (Sigma-Aldrich, St Louis, Mo), and cobalt chloride $\left(\mathrm{CoCl}_{2}\right.$; Sigma-Aldrich) for 12 hours followed by incubation at $37^{\circ} \mathrm{C}$ in humidified $5 \% \mathrm{CO}_{2}$ conditions.

\section{Immunofluorescence}

$1 \times 10^{4}$ of hPD-MSCs and hBM-MSCs were seeded on a $24 \times 55-\mathrm{mm}$ microscope cover glass in 6-cm cell-culture dishes. Subsequently, cells were fixed with ice-cold acetone, blocked with $2 \%$ bovine serum albumin, 
and incubated with rabbit anti-CXCR4 (1:250; Abcam, Cambridge, United Kingdom) at $4^{\circ} \mathrm{C}$ overnight. Afterwards, Alexa Fluor 488 donkey antirabbit secondary antibody (Abcam) was added for 2 hours. Cells were then observed under a fluorescent microscope (Model-BX40; Olympus, Tokyo, Japan). Nuclei were stained with 4',6-diamidino-2-phenylindole.

\section{Cell Migration Assay}

The Transwell cell migration assay was performed as described by the manufacturer (Corning, Tewksbury, Mass). In brief, $1 \times 10^{5}$ in triplicates of hPD-MSCs and hBM-MSCs in DMEM were seeded in the upper chambers of the Transwell plates (Corning). SDF- $1 \alpha$ in DMEM $(0-800 \mathrm{ng} / \mathrm{mL})$ was placed in the lower chambers. In some conditions, CXCR4 inhibitor (AMD3100 at $500 \mathrm{ng} / \mathrm{mL}$ ) was added to the cells in the upper chamber. Migrated cells towards SDF- $1 \alpha$ (to the back of the filter) were counted after 12 hours of incubation at $37^{\circ} \mathrm{C}$.

\section{Live Dead Assay}

$1 \times 10^{5}$ of hPD-MSCs and hBM-MSCs were seeded in 24-well plates (Corning). Cells were seeded in the presence of SDF-1 $\alpha(0-400 \mathrm{ng} / \mathrm{mL})$, glucose $(0-800 \mathrm{mM})$, and $\mathrm{CoCl}_{2}(0-800 \mu \mathrm{M})$. Optimized concentrations of each condition were chosen. Live cells were counted after 24 hours of incubation at $37^{\circ} \mathrm{C}$. Cell viability was calculated $(\mathrm{S}=$ Sample; $\mathrm{C}=$ Control; $\mathrm{A}=$ Alive; $\mathrm{T}=$ Total; Cell viability $[\%]=[\mathrm{SA} / \mathrm{ST}] /[\mathrm{CA} /$ $\mathrm{CT}] \times 100 \%)$.

\section{Cell Proliferation Assay}

$1 \times 10^{4}$ cells were seeded into 96-well plates in phenol-red free medium. SDF- $1 \alpha(100 \mathrm{ng} / \mathrm{mL}), \mathrm{CoCl}_{2}(400 \mu \mathrm{M})$, or glucose $(50 \mathrm{mM})$ was then added for 3 different time periods: 6, 12, and 24 hours. Afterwards, the 3-(4,5-dimethylthiazol-2-yl)-2,5-diphenyltetrazolium bromide proliferation assay was initiated as described by the manufacturer (Life Technologies, Carlsbad, Calif). Plates were then incubated overnight and analyzed for absorbance at $570 \mathrm{~nm}$ in a plate reader (TECAN, Männedorf, Switzerland). Optimized times were chosen for cell culture.

\section{RNA Isolation and Semiquantitative Reverse-}

\section{Transcription Polymerase Chain Reaction (RT-PCR)}

Total RNA was isolated with an RNeasy Plus Mini Kit (QIAGEN, Germantown, Md). Gene expression was detected by semiquantitative RT-PCR. Sequences of forward and reverse primer pairs are as follows: human CXCR4 forward: 5-GGTGGTCTATGTTGGCGTCT-3; reverse: 5-TGGAGTGTGACAGCTTGGAG-3 and human glyceraldehyde 3phosphate dehydrogenase forward: 5-ATGTTCGTCATGGGTGTGAA CC-3; reverse: 5-GGCAGGTTTTTCTAGACGGCAG-3.

\section{Western Blot}

Western blot was conducted via a standard protocol. To summarize, lysed proteins were electrophoresed using a $10 \%$ sodium dodecyl sulfate polyacrylamide gel electrophoresis then transferred onto a polyvinylidene difluoride membrane (Bio-Rad, Hercules, Calif). Subsequently, the blotting membrane was incubated overnight at $4^{\circ} \mathrm{C}$ with primary antibodies for Akt, phosphorylated Akt (p-Akt), extracellular signal-regulated kinase (ERK), phosphorylated ERK (p-ERK), $\alpha$-tubulin (Cell Signaling, Danvers, Mass) and beta-actin, CXCR4, hypoxia-inducible factor- $1 \alpha$, interleukin-6 (IL-6; Santa Cruz Biotechnology, Santa Cruz, Calif). Specific horseradish peroxidase-conjugated secondary antibodies were then applied, and Western Lightning Plus-ECL (PerkinElmer, Waltham, Mass) was used to visualize the reaction product.

\section{Fluorescence-Activated Cell Sorting (FACS)}

$8 \times 10^{6}$ hPD-MSCs and hBM-MSCs were incubated with rabbit antiCXCR4 primary antibody (1:250; Abcam), then donkey anti-rabbit Alexa

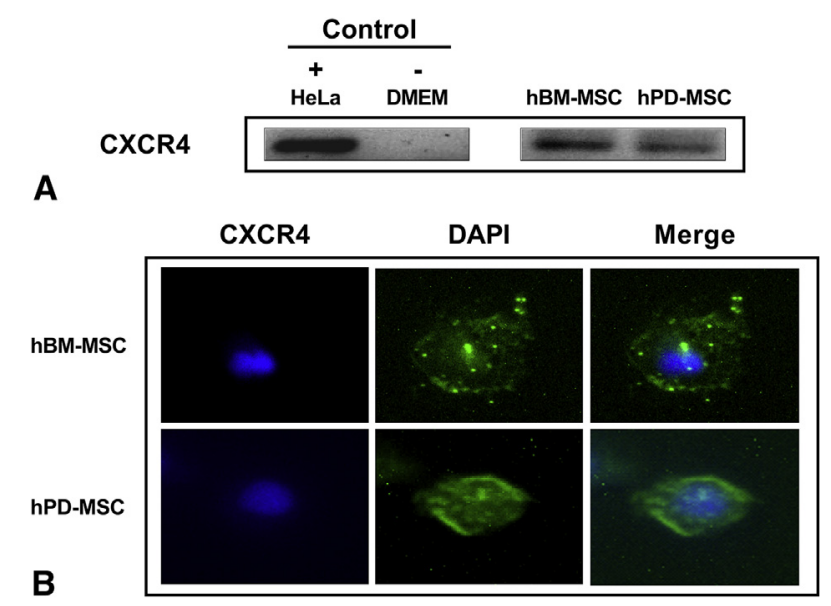

FIGURE 1. CXCR4 expression in hPD-MSCs and hBM-MSCs. A, Gene expression of CXCR4 was detected in nontreated hPD-MSCs and hBM-MSCs by semiquantitative RT-PCR. Naturally expressing HeLa cells were taken as a positive control and DMEM was treated as a negative control. B, As observed by fluorescence microscopy, CXCR4 was expressed on the plasma membrane of nonpermeabilized hPD-MSCs and hBM-MSCs. CXCR4 is stained in green (Alexa Fluor 488), and the nucleus is stained with DAPI in blue. HeLa, Henrietta Lacks cell line; DMEM, Dulbecco's modified Eagle's medium; hBM-MSCs, human bone marrowderived mesenchymal stem cells; $h P D-M S C s$, human placenta-derived mesenchymal stem cells; CXCR4, C-X-C chemokine receptor type 4; DAPI, 4',6-diamidino-2-phenylindole.

Fluor 488 secondary antibody (1:250; Abcam). Cells in the top $15 \%$ of CXCR4 expression were sorted from each group. Data were analyzed with a BD FACSARIA analyzer (BD, Franklin Lakes, NJ) fitted with BD FACSDiva software.

\section{Statistical Analysis}

Experiments were conducted in triplicates and compared by the use of analysis of variance. Results were analyzed at a significance level of $P<.05$. Graphs were plotted using GraphPad Prism 7.0 (GraphPad, La Jolla, Calif). In the figures, ${ }^{*} P<.05, * * P<.01, * * * P<.001$, $* * * * P<.0001$.

\section{RESULTS}

\section{CXCR4 Expression was Detected in Both hPD-MSCs and hBM-MSCs}

The expression of CXCR4 was detected in hPD-MSCs as well as in hBM-MSCs at the mRNA level through semiquantitative RT-PCR. HeLa cells were taken as a positive control and DMEM (without cells) was taken as a negative control as shown in Figure 1, $A$. In Figure 1, $B$, CXCR4 was expressed on the plasma membrane in nonpermeabilized hPD-MSCs and hBM-MSCs as observed by fluorescence microscopy.

\section{hPD-MSCs Have Stronger Cell Migration Responsiveness Toward SDF-1 $\alpha$}

As shown in Figure 2, A, cell migration of hPD-MSCs was compared with hBM-MSCs by the Transwell cell migration 
Comparative Cell Migration Assay

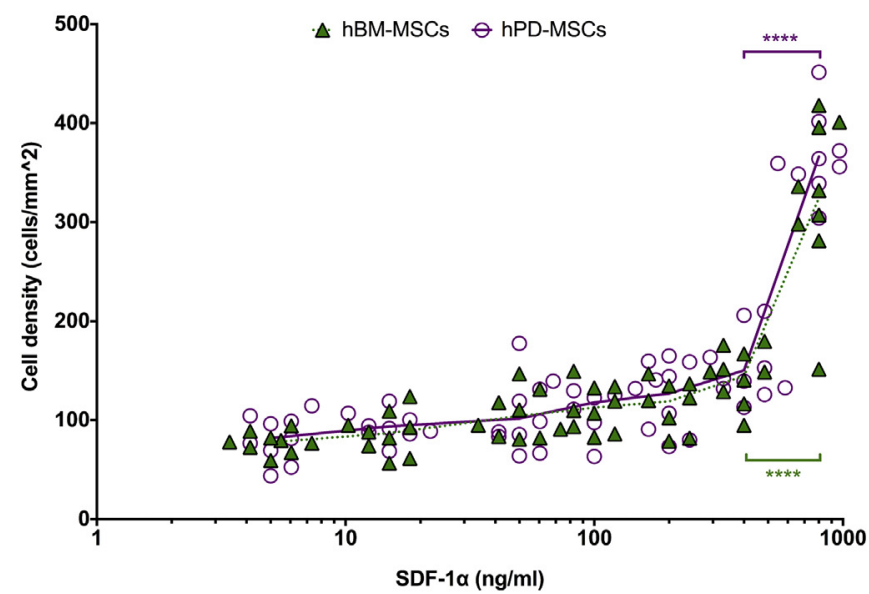

A
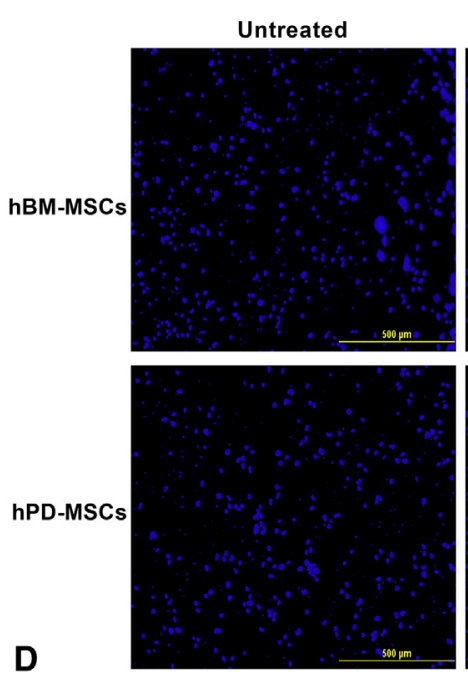

$800 \mathrm{ng} / \mathrm{ml}$ SDF-1 $\alpha$
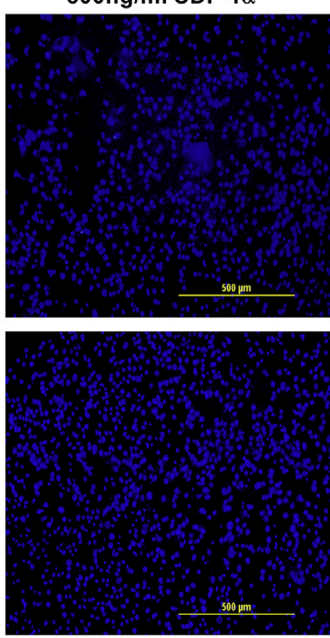

hBM-MSCs

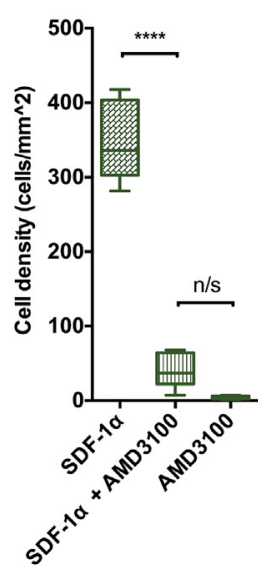

B
hPD-MSCs

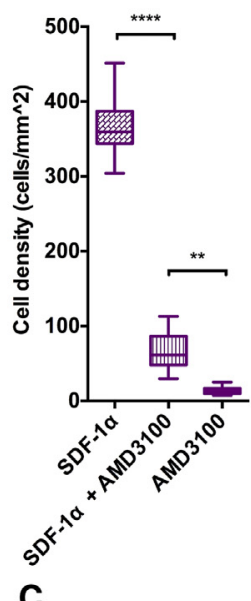

C

FIGURE 2. Growth factor (SDF-1 $\alpha$ )/chemokine receptor (CXCR4)-dependent cell migration in hBM-MSCs and hPD-MSCs. A, hPD-MSCs were compared in cell migration with hBM-MSCs $(\mathrm{n}=9)$. In $(\mathrm{B})$ and $(\mathrm{C})$, SDF- $1 \alpha / \mathrm{CXCR} 4$ axis dependent cell migration pathway was tested in the absence and presence of AMD3100 (CXCR4 antagonist) which indicates the involvement of other chemotactic/cell migratory pathways. D, Migratory cells were counted by ImageJ software. The nucleus is stained with DAPI in blue. Error bars represent means \pm SD of 3 independent experiments performed in triplicate $(\mathrm{n}=9)$. hBM-MSCs, Human bone marrow-derived mesenchymal stem cells; $h P D-M S C s$, human placenta-derived mesenchymal stem cells; $S D F-1 \alpha$, stromal-derived factor-1 alpha; $n / s$, not significant.

assay. Cell migration data were plotted on a $\log _{10}$ scale. In the Transwell migration assay, hPD-MSCs were more sensitive to the increasing concentrations of SDF- $1 \alpha$, showing greater migration rates $\left(\mathrm{Y}_{0}=80.40 \pm 7.89 ; \mathrm{R}^{2}=0.8866\right)$ than hBM-MSCs $\left(\mathrm{Y}_{0}=77.13 \pm 9.99 ; \mathrm{R}^{2}=0.6949\right)$ from nonlinear fit curve analysis when the exponential growth equation was used. In Figure 2, $B$ and $C$, dependency on the SDF- $1 \alpha /$ CXCR 4 axis was evaluated with and without the presence of a CXCR4 antagonist (AMD3100 at $500 \mathrm{ng} /$ $\mathrm{mL})$ and SDF- $1 \alpha(800 \mathrm{ng} / \mathrm{mL})$. AMD3100 significantly reduced cell migration more in hPD-MSCs $(366.31 \pm 41.27$ to $16.29 \pm 2.55)$ than in hBM-MSCs $(352.86 \pm 52.65$ to $3.63 \pm 1.02)$. Unlike hBM-MSCs,
hPD-MSCs had a significant difference $(P<.01)$ between the AMD3100 + SDF- $1 \alpha$ and AMD3100 groups, indicating the involvement of other chemotactic/migratory pathways apart from the SDF- $1 \alpha /$ CXCR 4 axis.

\section{$\mathrm{CXCR4}^{+}$hPD-MSCs Significantly Increased After $\mathrm{CoCl}_{2}$-Induced Hypoxic Treatment}

Cellular viability and proliferation of hPD-MSCs and hBM-MSCs were optimized with different concentrations of SDF- $1 \alpha$, glucose, and $\mathrm{CoCl}_{2}$ (Figures E1 and E2). Subsequently, using the optimized concentrations of SDF- $1 \alpha$, glucose, and $\mathrm{CoCl}_{2}(100 \mathrm{ng} / \mathrm{mL}, 50 \mathrm{mM}$, and $400 \mu \mathrm{M}$, respectively), we determined the expression of 


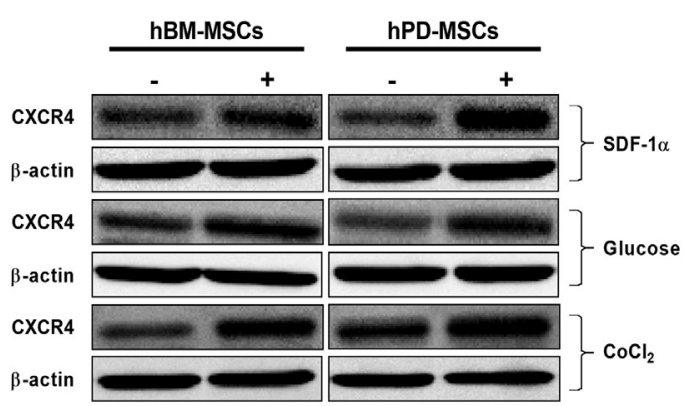

Relative Expression of CXCR4

A

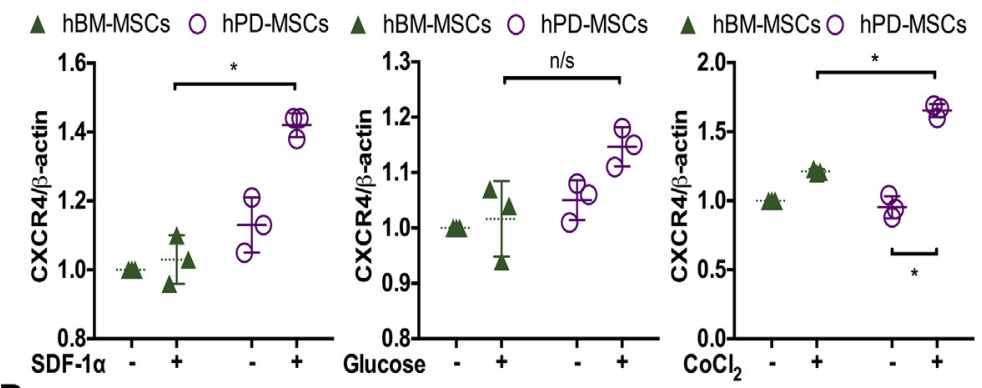

$\triangle$ hBM-MSCsO hPD-MSCs

B
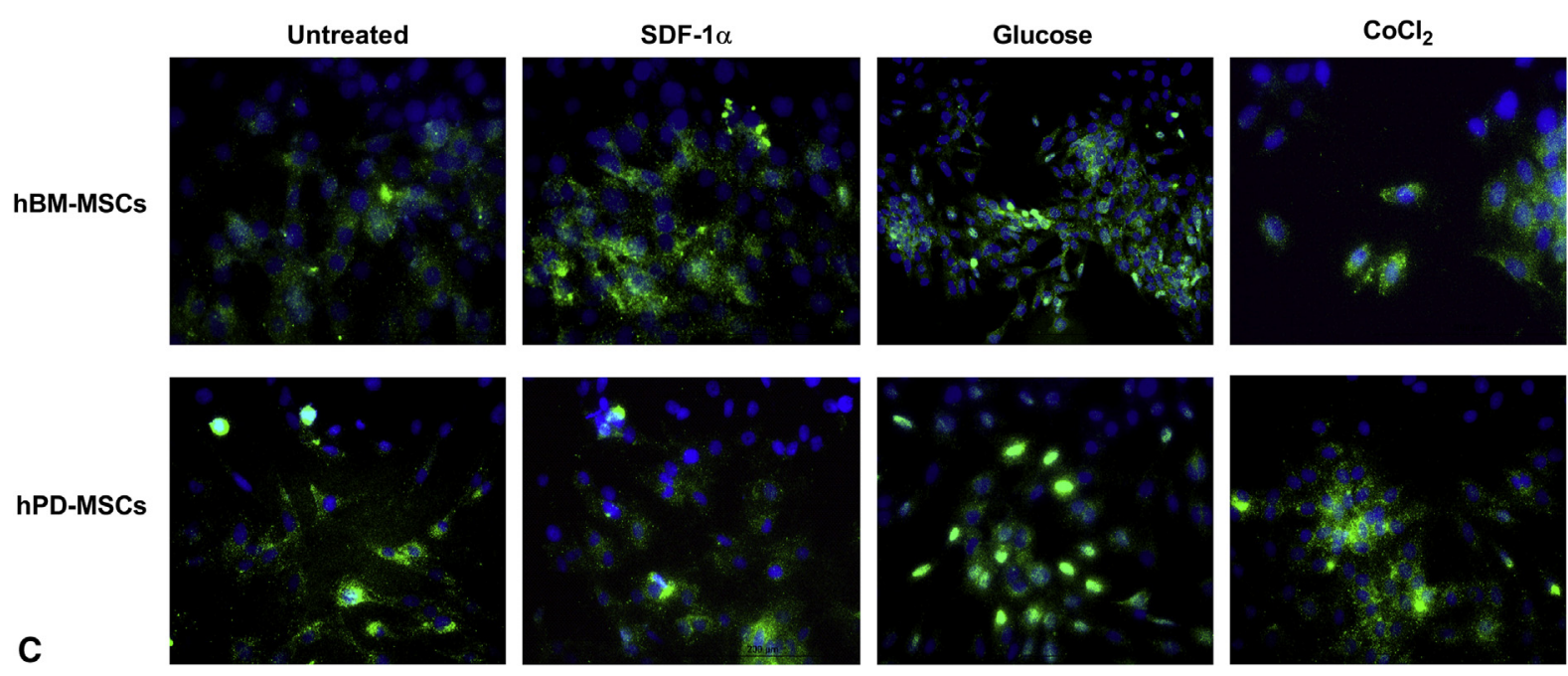

FIGURE 3. CXCR4 expression in different conditions (untreated, SDF- $1 \alpha$, glucose, and $\mathrm{CoCl}_{2}$ ). A, CXCR4 expression tested in hBM-MSCs and hPD-MSCs exposed to different conditions by Western blot. B, Glucose treatment had no significant difference on CXCR4 expression in either cells, whereas it was significantly increased $(P<.05)$ after SDF- $1 \alpha$ and $\mathrm{CoCl}_{2}$-induced hypoxia treatment. C, Fluorescence images showing the increased expression of CXCR4 in hPD-MSCs and hBM-MSCs treated with SDF- $1 \alpha$ and $\mathrm{CoCl}_{2}$-induced hypoxia. CXCR4 is stained in green, and DAPI in blue stains the nucleus. Bars represent means $\pm \mathrm{SD}$ of experiments performed in triplicates. $h B M-M S C s$, Human bone marrow-derived mesenchymal stem cells; hPD-MSCs, human placenta-derived mesenchymal stem cells; CXCR4, C-X-C chemokine receptor type 4; SDF-1 $\alpha$, stromal-derived factor-1 alpha; $\mathrm{CoCl}_{2}$, cobalt chloride; $n / s$, not significant.

CXCR4 on hBM-MSCs and hPD-MSCs and compared as shown in Figure $3, A$ and $B$. Results indicated that glucose treatment had no significant difference on CXCR4 expression in either cells, whereas CXCR4 expression was significantly increased after SDF- $1 \alpha$ treatment in hPD-MSCs (from $1.13 \pm 0.0800$ to $1.41 \pm 0.0346$ ) compared with hBM-MSCs (from 1 to $1.03 \pm 0.0700$ ). In addition, CXCR4 expression also was found to significantly increase in response to $\mathrm{CoCl}_{2}$-induced hypoxia in hPDMSCs (from $0.95 \pm 0.0808$ to $1.65 \pm 0.0473$ ) compared with hBM-MSCs (from 1 to $1.21 \pm 0.0123$ ) (Table E1). This observation was confirmed by immunofluorescence images, as shown in Figure 3, $C$.

To further substantiate the increased $\mathrm{CXCR}^{+}$ expression on hPD-MSCs in $\mathrm{CoCl}_{2}$-induced hypoxia, FACS analysis was performed to sort the $\mathrm{CXCR} 4^{+}$cells (Figure 4, A). The $\mathrm{CXCR}^{+}{ }^{+}$hBM-MSCs population increased by 2 -fold $(3.00 \% \pm 0.3265$ to $7.50 \% \pm$ 0.4752), whereas CXCR $4^{+}$hPD-MSCs population was significantly increased by 10 -fold $(3.79 \% \pm 0.4751$ to $31.75 \% \pm 1.2451$ ) as shown in Figure 4, $B$ (Figure E3 and Table E2).

\section{Phosphorylated Akt (p-Akt) and Phosphorylated ERK (p-ERK) Expression Were Significantly} Increased in $\mathrm{CoCl}_{2}$-Induced Hypoxic hPD-MSCs

In $\mathrm{CoCl}_{2}$-induced hypoxia, hypoxia-inducible factor- $1 \alpha$ expression was increased, and this change was evident in Western blots of both hPD-MSCs and hBM-MSCs (Figure 5, A). As shown in Figure 5, B, the relative expression of p-Akt to total Akt in both hBM-MSCs and hPD-MSCs was significantly greater ( 1 to $3.53 \pm 0.2486$ and $1.64 \pm 0.4035$ to $3.09 \pm 0.5242$, respectively) in hypoxic than in normoxic conditions (Table E3). However, 


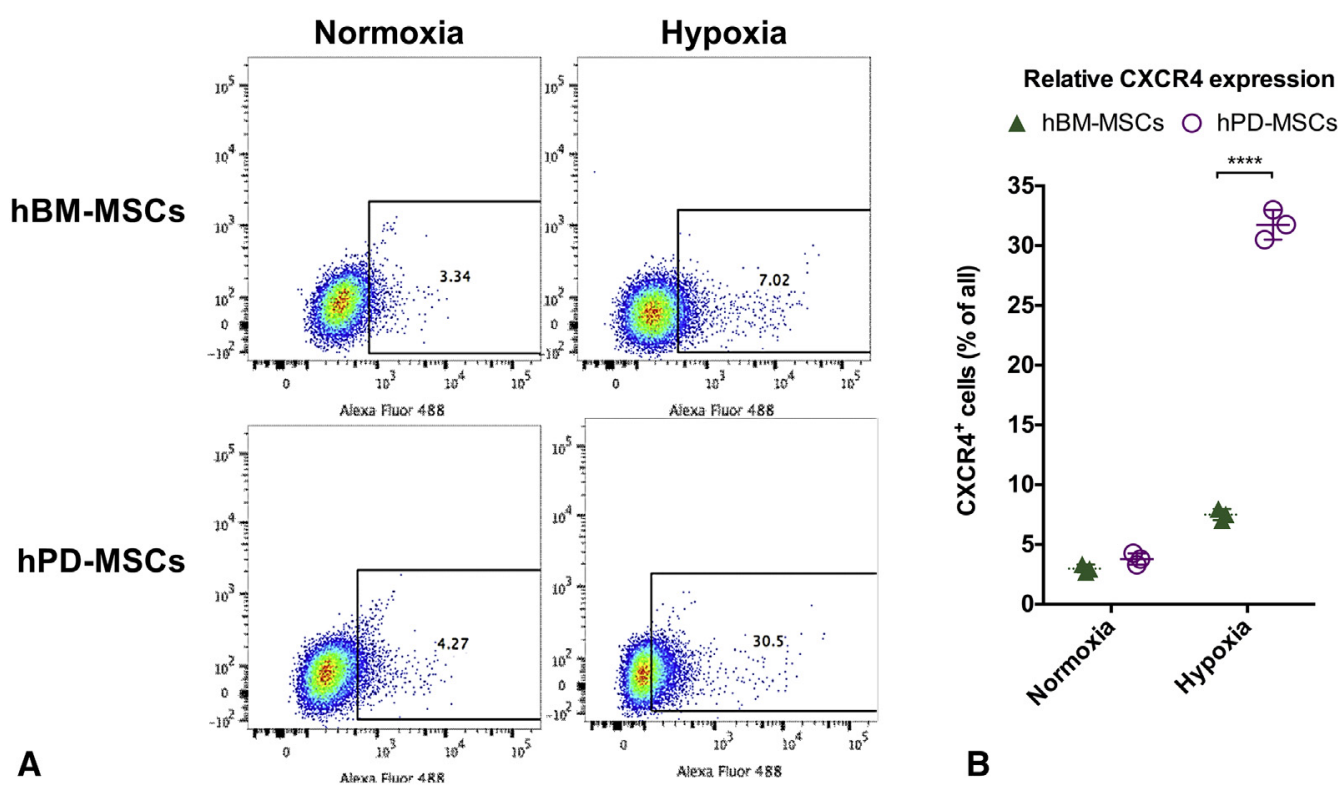

FIGURE 4. Relative $\mathrm{CXCR}^{+}$cell expression in $\mathrm{CoCl}_{2}$-induced hypoxia. A, Cell sorting of $\mathrm{CXCR}^{+}{ }^{+}$cells. $\mathrm{B}, \mathrm{In} \mathrm{CoCl}_{2}$-induced hypoxia, $\mathrm{CXCR} 4$ expression was significantly greater $(P<.001)$ in hPD-MSCs $(10$-fold) compared with hBM-MSCs $(2$-fold). Bars represent means \pm SD of experiments performed in triplicates. $h B M-M S C s$, Human bone marrow-derived mesenchymal stem cells; $h P D-M S C s$, human placenta-derived mesenchymal stem cells; CXCR4, C-X-C chemokine receptor type 4.

the relative expression of p-ERK to total ERK was significantly greater in hPD-MSCs $(0.92 \pm 0.0237$ to $1.12 \pm 0.0240$ ) in contrast to hBM-MSCs (Figure 5, $C$ and Table E3).

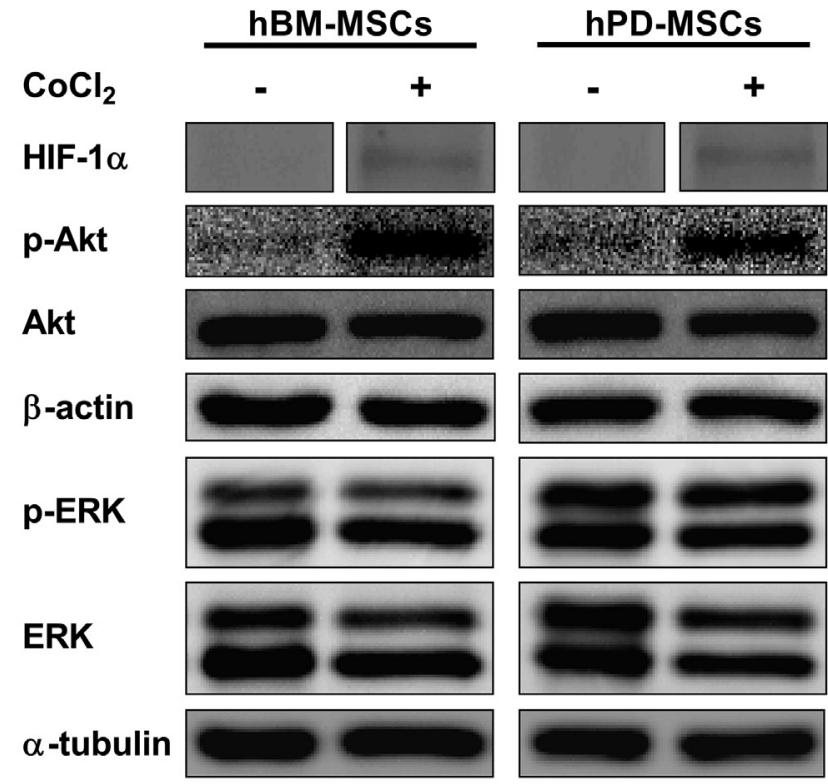

\section{A}

\section{IL-6 Expression Significantly Decreased in $\mathrm{CoCl}_{2-}$ Induced Hypoxic Conditions}

As shown in Figure 6, $A$ and $B$, IL-6 expression was significantly decreased in both hPD-MSCs $(P<.001)$ and

FIGURE 5. HIF- $1 \alpha$, p-Akt, and p-ERK expression in $\mathrm{CoCl}_{2}$-induced hypoxia. A, HIF- $1 \alpha$ expression was increased, and it was detected in both hPD-MSCs and hBM-MSCs. B, The relative expression of p-Akt to total Akt was significantly greater $(P<.01)$ in hBM-MSCs and in hPD-MSCs. C, The relative expression of p-ERK to total ERK was significantly greater $(P<.01)$ in hPD-MSCs, whereas in hBM-MSCs, it was not significant. Bars represent means $\pm \mathrm{SD}$ of experiments performed in triplicate. hBM-MSCs, Human bone marrow-derived mesenchymal stem cells; hPD-MSCs, human placenta-derived mesenchymal stem cells; $\mathrm{CoCl}_{2}$, cobalt chloride; $H I F-1 \alpha$, hypoxia-inducible factor- $1 \alpha ; p$ - $A k t$, phosphorylated Akt; $A k t$, protein kinase $\mathrm{B} ; p-E R K$, phosphorylated ERK; $E R K$, extracellular signal-regulated kinase; $n / s$, not significant. 


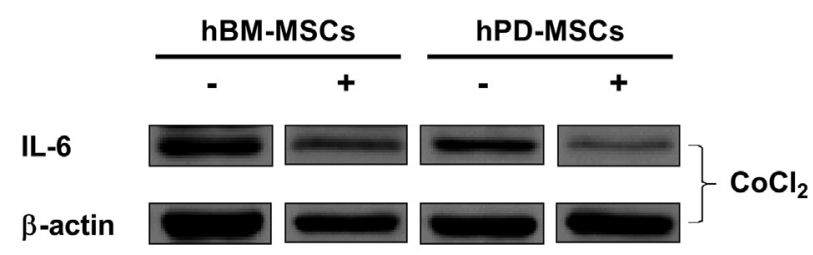

A

\section{Relative IL-6 Intensity}

$\Delta$ hBM-MSCs O hPD-MSCs

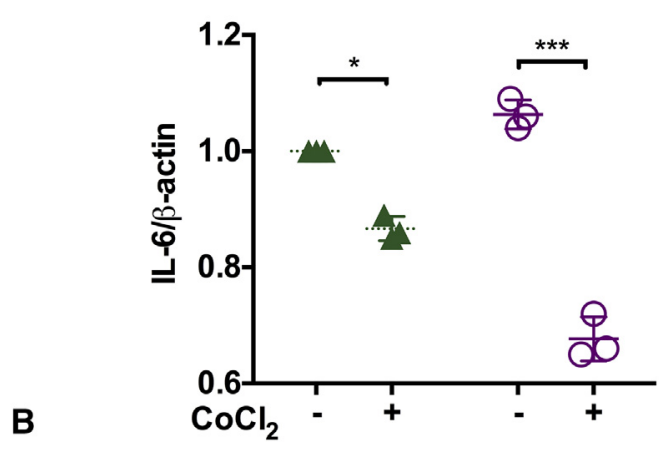

FIGURE 6. IL-6 expression in $\mathrm{CoCl}_{2}$-induced hypoxia (A). IL-6 expression was significantly decreased in both hPD-MSCs $(P<.001)$ and hBM-MSCs $(P<.05)$ as observed by Western blot $(B)$. Bars represent means $\pm \mathrm{SD}$ of experiments performed in triplicate. $h B M-M S C s$, Human bone marrow-derived mesenchymal stem cells; hPD-MSCs, human placenta-derived mesenchymal stem cells; $I L-6$, interleukin-6; $\mathrm{CoCl}_{2}$, cobalt chloride.

hBM-MSCs $(P<.05)$ after the exposure to $\mathrm{CoCl}_{2}$-induced hypoxia (Table E3).

\section{DISCUSSION}

Cardiac ischemia may lead to MI, and this causes an irreversible loss of cardiomyocytes directly related to their innate insufficient regenerative capacity. ${ }^{2} \mathrm{hBM}-\mathrm{MSC}$ s have been studied widely in myocardial regeneration because of their beneficial effects on tissue repair and the potential to differentiate into cardiomyocytes. However, the modest improvement in clinical trials with the use of MSCs for MI treatment suggests that more understanding of the stem cell biology is required. ${ }^{13}$ This limited success often has been linked with poor cell migration, cell retention, and cell survival. ${ }^{14}$ In addition, the route of MSC administration can significantly affect the repairing process of the infarcted heart and hence the clinical outcome. Accumulating evidence suggests that MSCs directly injected into the ischemic region of the heart have shown better cell retention than other administration routes. ${ }^{15}$

After a cardiac infarction event, cardiomyocytes begin secreting growth factors such as SDF- $1 \alpha$. As a result, specific chemokines like the CXCR4 are activated on the MSCs, which start migrating along the increasing gradient of SDF- $1 \alpha$ to finally reach the infarction zone. These MSCs would then participate in the cardiac repair process through transdifferentiation, cell-fusion, and/or by paracrine secretions. ${ }^{2}$ Very few experimental studies have demonstrated that hPD-MSCs could be a suitable alternative to hBM-MSCs in improving cardiac function of an infarcted myocardium. It was observed that the significant improvement detected mostly was caused by paracrine secretions of MSCs without the need of permanent cell engraftment. ${ }^{12}$

The scope of this study is limited to investigating the cellular migration process, which is one of the most important bottlenecks in MSCs therapy of MI. Although CXCR4 expression is similar in hPD-MSCs and hBM-MSCs (Figure 1), hPD-MSCs have shown a greater sensitivity to SDF- $1 \alpha$ concentrations (Figure 2, A). In laboratory conditions, significant changes in CXCR4 expression were observed in hBM-MSCs and hPD-MSCs after the use of optimized doses of SDF- $1 \alpha-$ and $\mathrm{CoCl}_{2}$-induced hypoxia (Figure 3; Figures E1 and E2). Cell migration was significantly suppressed in hPD-MSCs and hBM-MSCs in the presence of AMD3100 (CXCR4 antagonist). It also was found that hPD-MSCs (not hBM-MSCs) were significantly migrating towards SDF- $1 \alpha$, despite the presence of a CXCR 4 inhibitor (AMD3100) (Figure 2). This finding indicates 3 hypotheses.

An alternative chemotactic/migratory pathway different from the SDF- $1 \alpha / \mathrm{CXCR} 4$ pathway was activated in hPD-MSCs. Such alternatives include the IL-6-dependent cell migration signaling. ${ }^{19}$ The latter hypothesis is unlikely involved, since our results indicate that IL-6 expression pattern was similar in both hPD-MSCs and hBM-MSCs under $\mathrm{CoCl}_{2}$-induced hypoxic conditions (Figure 6).

HPD-MSCs could have an increased sensitivity toward lower amounts of CXCR4. After the activation of the SDF- $1 \alpha /$ CXCR 4 axis, various complex downstream signaling cascades are activated, particularly the PI3K/ Akt and the mitogen-activated protein kinase kinase (MEK)/ERK/I $\kappa \beta$ kinase $\alpha \beta$ pathways, which activate various transcription factors implicated in tissue repair such as the NF $\kappa \mathrm{B}$, leading ultimately to CXCR4 secretion. ${ }^{17}$ Our results showed that the ratio of p-ERK to total ERK was significantly up-regulated in hPD-MSCs. In contrast, the p-Akt to total Akt ratio was increased in hBM-MSCs (Figure 5). Apart from the SDF-1 $\alpha /$ CXCR4 axis, other chemokines such as the CXCR7 receptors are engaged with SDF- $1 \alpha$ after an ischemic myocardial event. Thus, hBM-MSCs and hPD-MSCs could be following different cell migration and proliferation patterns, in particular the CXCR4/Akt and CXCR4/MEK/ERK pathways. ${ }^{18}$

In a simulated myocardial ischemia, a 10 -fold increase in the $\mathrm{CXCR}^{+}{ }^{+}$hPD-MSCs population was observed in response to $\mathrm{CoCl}_{2}$-induced hypoxia. In contrast, only a 


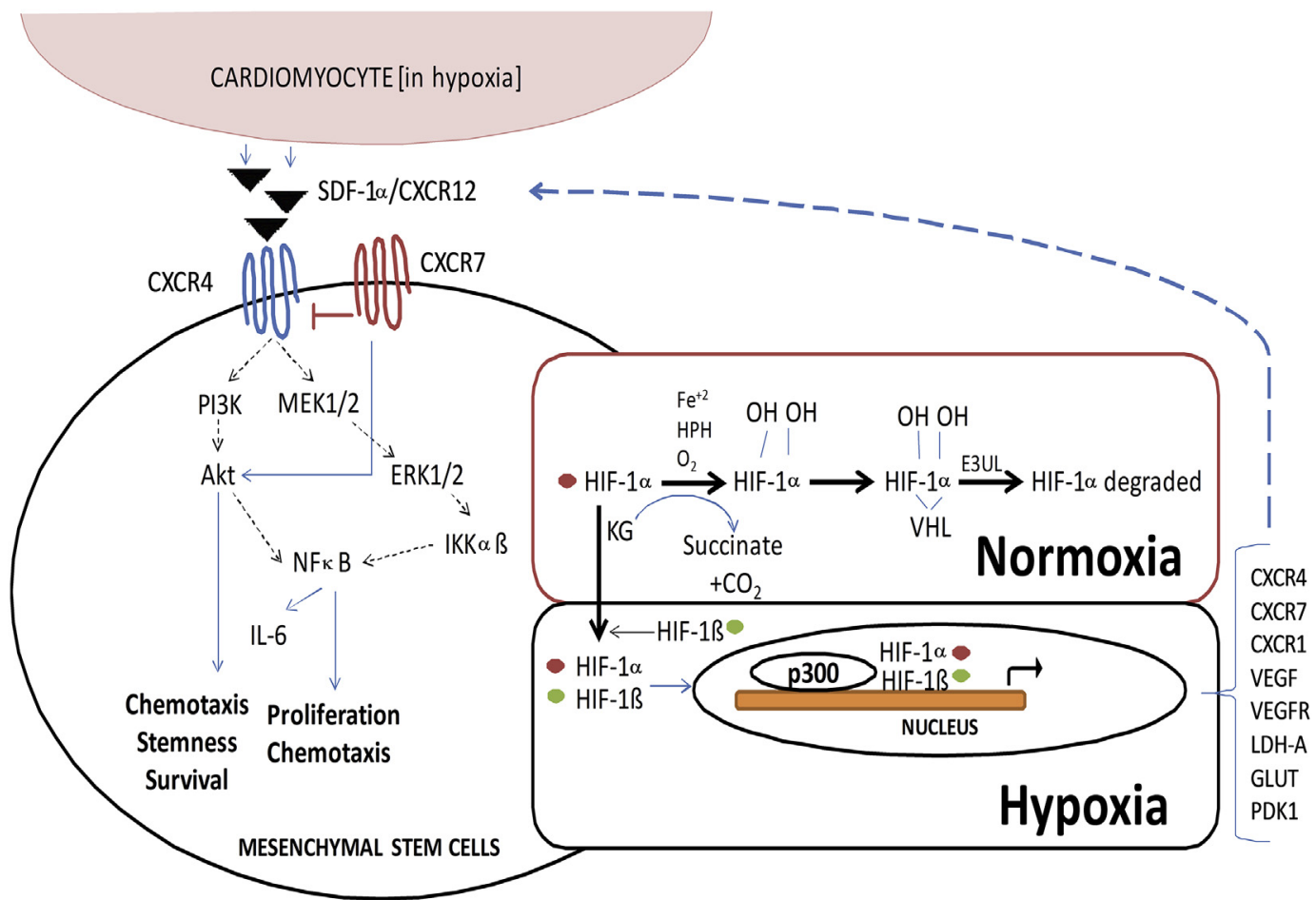

FIGURE 7. Proposed pathway for improved cell migration in hPD-MSCs. In acute myocardial infarction, cardiomyocytes start secreting growth factors such as SDF-1 $\alpha$ (CXCR12), which binds to the chemokine surface receptor CXCR4 on the MSCs and triggers a downstream signaling effect. Two main pathways (PI3K/Akt and MEK/ERK/IKK $\alpha \beta$ ) are modulated to trigger NFKB translocation into the nucleus. This in term increases the release of paracrine factors, including CXCR4, VEGF, and VEGF-R. The latter will help in cell migration along the gradient of SDF- $1 \alpha$, proliferation, and the survival of MSCs. HPD-MSCs sensitivity for MEK/ERK/IKK $\alpha \beta$ pathway is relatively greater than hBM-MSCs sensitivity, resulting in greater expression of CXCR4 ${ }^{+}$cells in hypoxia. $S D F-1 \alpha$, Stromal-derived factor-1 alpha; $C X C R 12$, chemokine receptor type 12; CXCR4, C-X-C chemokine receptor type 4; $C X C R 7, \mathrm{C}-\mathrm{X}-\mathrm{C}$ chemokine receptor type 7; PI3K, phosphatidylinositol 3-kinase; $M E K$, mitogen-activated protein kinase kinase; Akt, protein kinase B; ERK, extracellular signal-regulated kinase; $N F \kappa B$, nuclear factor $\kappa \beta ; I K K \alpha \beta, \mathrm{I} \kappa \beta$ kinase $\alpha \beta ; I L-6$, interleukin-6; HIF-1 $\alpha$, hypoxia-inducible factor- $1 \alpha$; $F e$, ferrous ion; $H P H$, HIF prolyl hydroxylase; VHL, Von Hippel-Lindau tumor suppressor; HIF-1 $\beta$, hypoxia-inducible factor-1 $\beta$; $C X C R 1$, C-X-C chemokine receptor type 1; VEGF, vascular endothelial growth factor; VEGFR, vascular endothelial growth factor receptor; $L D H-A$, lactate dehydrogenase A; GLUT, glucose transporter; $P D K-1$, pyruvate dehydrogenase kinase-1.

2-fold increase in the $\mathrm{CXCR} 4^{+} \mathrm{hBM}-\mathrm{MSCs}$ population was detected (Figure 4).

The commitment to a distinct signaling pathway and the increase in the number of CXCR $4^{+}$hPD-MSCs partly could explain the increased chemotactic response of hPD-MSCs in an ischemic microenvironment (Figure 7). To further validate this theory, an in-depth analysis of relevant transcription factors such as $\mathrm{NF} \kappa \mathrm{B}$ should be conducted. Along with that, the signaling cascades should be investigated for any connection with placental specific factors such as the placenta-induced growth factor. Placenta-induced growth factor is natively present in placental cells; it enhances cell motility by mobilizing ERK phosphorylation and cytoskeletal rearrangement in various kinds of cells.

Although there are lesser ethical concerns in the use of hPD-MSCs, multiple factors remain to overcome to achieve a better clinical outcome. For example, a better understanding of cellular retention, homing, adhesion, and a spatial arrangement in a lattice-like form for a functional integration with the native tissues are required. Indeed, the use of appropriate biomaterials with hPD-MSCs can have a significant impact on minimizing the aforementioned challenges. ${ }^{2,6,15,20}$

\section{Hypoxia Modulates Cell Migration and Proliferation in Placenta-Derived Mesenchymal Stem Cells}

Li Li, MSc $c^{a}$, Prashant K. Jaiswal, PhD ${ }^{\mathrm{b}}$, Georges Makhoul, MD, MSc ${ }^{2}$, Rishi Jurakhan, MSc $^{2}$, Kaviyanka Selvasandran, MSc ${ }^{2}$, Khalid Ridwan, MD, MSc ${ }^{2}$, Renzo Cecere, MD $^{\mathrm{a}, b^{*}}$

a'Division of Experimental Surgery, McGill University, Montreal, Canada bivision of Cardiac Surgery, McGill University Health Centre, Montreal, Canad *Corresponding author

VIDEO 1. hPD-MSCs as an effective alternative to hBM-MSCs with a higher sensitivity to the SDF1- $\alpha$ /CXCR4 axis. hPD-MSCs, Human placenta-derived mesenchymal stem cells; $h B M-M S C s$, human bone marrow-derived mesenchymal stem cells; $S D F-1 \alpha$, stromal-derived factor-1 alpha; $C-X-C$, chemokine receptor type 4 . Video available at: http://www.jtcvsonline.org/article/S0022-5223(17)30702-X/addons. 


\section{CONCLUSIONS}

This study indicates that both hBM-MSCs and hPD-MSCs express the CXCR4 chemokine in hypoxic conditions. The greater sensitivity for the growth factor SDF- $1 \alpha$-dependent cell migration of hPD-MSCs than hBM-MSCs is well aligned with the greater expression of CXCR4 in the presence of SDF- $1 \alpha$. In response to hypoxia, a 10 -fold increase in $\mathrm{CXCR} 4^{+}$hPD-MSCs was observed, whereas only a 2 -fold increase in $\mathrm{CXCR} 4^{+}$hBM-MSCs was found. Contrary to hBM-MSCs, in which the CXCR4/Akt pathway was dominantly activated, the CXCR4/MEK/ERK pathway was up-regulated in hPD-MSCs. This level of activation seems to cause a greater expression of CXCR4, and hence more cells become $\mathrm{CXCR} 4^{+}$. Taken together, our data provide new insights into the comparative molecular mechanisms that regulate MSC migration derived from different tissue sources (bone and placenta). We can conclude that hPD-MSCs may represent an effective and efficient alternative to hBM-MSCs for cytotherapy in ischemia induced diseases such as MI. A summary of this work can be find in supplementary Video 1.

\section{Webcast}

You can watch a Webcast of this AATS meeting presentation by going to: http://webcast.aats.org/2016/Video/ Tuesday/05-17-16_Ballroom_IV_0820_Li-800.mp4.

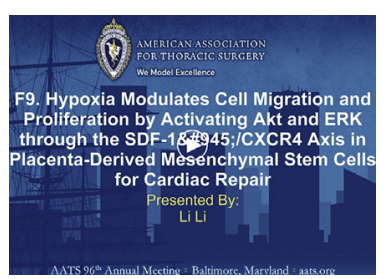

\section{Conflict of Interest Statement}

Authors have nothing to disclose with regard to commercial support.

The authors thank Ms Minh Ngoc Duong, Dr Lisbet Haglund and her laboratory staff for their technical support. They also acknowledge Dr Liqin Xu and Dr Shufeng Zhou for their valuable inputs.

\section{References}

1. World Health Organization. WHO Mortality Database update. Available at: http:// www.who.int/healthinfo/statistics/mortality_rawdata/en/(2015). Accessed May $21,2015$.

2. Ranganath SH, Levy O, Inamdar MS, Karp JM. Harnessing the mesenchymal stem cell secretome for the treatment of cardiovascular disease. Cell Stem Cell. 2012;10:244-58.

3. van Berlo JH, Molkentin JD. An emerging consensus on cardiac regeneration. Nat Med. 2014;20:1386-93.

4. Cai B, Li J, Wang J, Luo X, Ai J, Liu Y, et al. microRNA-124 regulates cardiomyocyte differentiation of bone marrow-derived mesenchymal stem cells via targeting STAT3 signaling. Stem Cells. 2012;30:1746-55.

5. Zhao JW, Zhang MR, Ji QY, Xing FJ, Meng LJ, Wang Y. The role of slingshot-1L (SSH1L) in the differentiation of human bone marrow mesenchymal stem cells into cardiomyocyte-like cells. Molecules. 2012;17:14975-94.

6. Lee MM, Li RK, Yau TM. Stem cell therapy for heart failure: out with the new and in with the old? J Thorac Cardiovasc Surg. 2015;150:1035-7.

7. Fukuhara S, Tomita S, Yamashiro S, Morisaki T, Yutani C, Kitamura S, et al. Direct cell-cell interaction of cardiomyocytes is key for bone marrow stromal cells to go into cardiac lineage in vitro. J Thorac Cardiovasc Surg. 2003;125: 1470-80.

8. Fedak PW, Szmitko PE, Weisel RD, Altamentova SM, Nili N, Ohno N, et al. Cell transplantation preserves matrix homeostasis: a novel paracrine mechanism. J Thorac Cardiovasc Surg. 2005;130:1430-9.

9. Garcia-Gomez I, Elvira G, Zapata AG, Lamana ML, Ramírez M, Castro JG, et al. Mesenchymal stem cells: biological properties and clinical applications. Expert Opin Biol Ther. 2010;10:1453-68.

10. Barlow S, Brooke G, Chatterjee K, Price G, Pelekanos R, Rossetti T, et al Comparison of human placenta- and bone marrow derived multipotent mesenchymal stem cells. Stem Cells Dev. 2008;17:1095-108.

11. Passipieri JA, Kasai-Brunswick TH, Suhett G, Martins AB, Brasil GV Campos DB, et al. Improvement of cardiac function by placenta-derived mesenchymal stem cells does not require permanent engraftment and is independent of the insulin signaling pathway. Stem Cell Res Ther. 2014;5:102.

12. Dong F, Harvey J, Finan A, Weber K, Agarwal U, Penn MS. Myocardial CXCR4 expression is required for mesenchymal stem cell mediated repair following acute myocardial infarction. Circulation. 2012;126:314-24.

13. Przybyt E, Harmsen MC. Mesenchymal stem cells: promising for myocardial regeneration? Curr Stem Cell Res Ther. 2013;8:270-7.

14. Chien KR. Stem cells: lost in translation. Nature. 2004:428:607-8

15. Hale SL, Dai W, Dow JS, Kloner RA. Mesenchymal stem cell administration at coronary artery reperfusion in the rat by two delivery routes: a quantitative assessment. Life Sci. 2008;83:511-5.

16. Gnecchi M, He H, Liang OD, Melo LG, Morello F, Mu H, et al. Paracrine action accounts for marked protection of ischemic heart by Akt-modified mesenchymal stem cells. Nat Med. 2005;11:367-8.

17. Tang CH, Chuang JY, Fong YC, Maa MC, Way TD. Bone-derived SDF-1 stimulates IL-6 release via CXCR4, ERK and NF-kappaB pathways and promotes osteoclastogenesis in human oral cancer cells. Carcinogenesis. 2008; 29:1483-92.

18. Chen D, Xia Y, Zuo K, Wang Y, Zhang S, Kuang D, et al. Crosstalk between SDF-1/CXCR4 and SDF-1/CXCR7 in cardiac stem cell migration. Sci Rep. 2015;5:16813.

19. Rattigan Y, Hsu J-M, Mishra PJ, Glod J, Banerjee D. Interleukin 6 mediated recruitment of mesenchymal stem cells to the hypoxic tumor milieu. Exp Cell Res. 2010;316:3417-24.

20. Duffy GP, Ahsan T, O'Brien T, Barry F, Nerem RM. Bone marrow-derived mesenchymal stem cells promote angiogenic processes in a time- and dose-dependent manner in vitro. Tissue Eng Part A. 2009;15:2459-70.

Key Words: placenta-derived mesenchymal stem cell, SDF-1 $\alpha$, CXCR4, cardiac infarction, cell migration, cell proliferation

\section{Discussion}

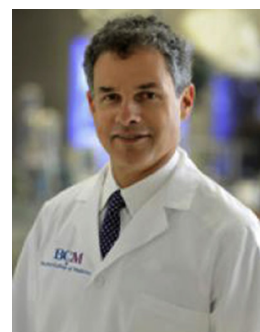

Dr Todd Rosengart (Houston, Tex). Thank you, Dr Li. That was a very nice presentation, and I appreciate receiving the manuscript in advance.

Your premise is that placentaderived MSCs are better because of greater efficiency and homing. Why not just double the dose of bone marrow-derived MSCs? Why is this advantageous other than greater efficiency? Not a bad thing, but is it important? 
Dr Li Li (Montreal, Quebec, Canada). We have a senior student who is doing her PhD in our laboratory, and she did in vivo testing on rats before, and she found that if we double the dose, the rats won't survive after 48 hours because of some complication of the cells that go to any other organs to block the vessels. That is why we chose another method.

Dr Rosengart. Very interesting. My second question is this. We have heard papers this morning about patches and local delivery of MSCs, and your premise and strategy is remote delivery and homing. Do you think homing remote delivery is a viable strategy, or do you think that all this work with patches is ultimately critical?

Dr Li. I think both ways are worth trying. We won't say no to novel techniques. So that is why our laboratory is focusing also on cell homing. We also have other residents, and most of the PhD students in our laboratory who are working on patches, also including hydrogels, and some other things. My project is just a subproject of the total thing.

Dr Rosengart. My last question is, the placenta-derived cells are allogeneic. Are there going to be issues in terms of rejection if this were a therapeutic strategy?

Dr Li. Pardon me?

Dr Rosengart. Are they allogenic or are they antigenic?

Dr Li. Yes.

Dr Rosengart. So is there a problem with rejection? How would you deliver these in a clinical scenario, do you know?

Dr Li. I cannot answer your question, because so far all my results are based on in vitro experiments. We have to further look at it in in vivo experiments in the future.

Readers who found these articles interesting may also like to read the following papers found in recent and future issues of our sister publications, Seminars in Thoracic and Cardiovascular Surgery and Operative Techniques in Thoracic and Cardiovascular Surgery!

Acquired: Basic Science

ORIGINAL SUBMISSION: Immediate Spinal Cord Collateral Blood Flow During Thoracic Aortic Procedures: The Role of Epidural Arcades. Fabian A. Kari. Semin Thoracic Surg 2016:378-387.

Editorial Commentary: Spinal Cord Collateral Pathways—-The Road Not Taken. Abe DeAnda Jr. Semin Thoracic Surg 2016:388-389. 
Cell Viability (SDF-1 $\alpha, 24 \mathrm{~h}$ )

$\triangle$ hBM-MSCs O hPD-MSCs

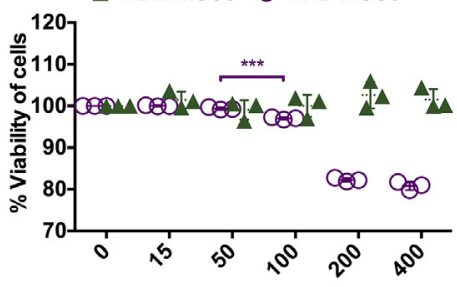

SDF-1 $\alpha$ Concentration (ng/mL)
Cell Viability (Glucose, 24h)

$\Delta$ hBM-MSCs O hPD-MSCs

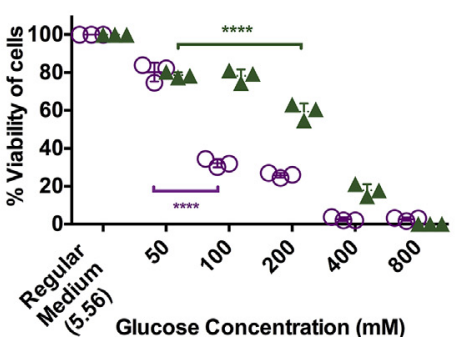

Cell Viability $\left(\mathrm{CoCl}_{2}, 24 \mathrm{~h}\right)$

$\Delta$ hBM-MSCs $\bigcirc$ hPD-MSCs

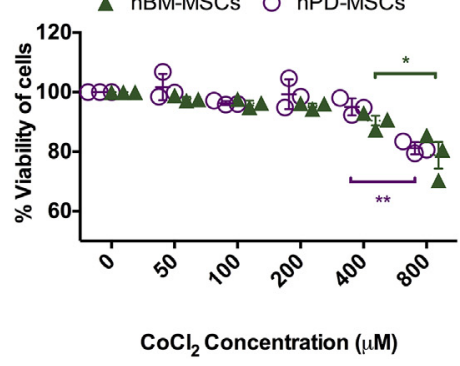

FIGURE E1. Cellular viability of hPD-MSCs and hBM-MSCs when exposed to different concentrations of SDF- $1 \alpha$, CoCl 2 , and glucose. Bars represent means \pm SD of 3 independent experiments performed in triplicates. hPD-MSCs, Human placenta-derived mesenchymal stem cells; $h B M-M S C s$, human bone marrow-derived mesenchymal stem cells; $S D F-1 \alpha$, stromal-derived factor-1 alpha; $\mathrm{CoCl}_{2}$, cobalt chloride.

Cell Proliferation (100ng/ml SDF-1 $\alpha$ )

$\triangle$ hBM-MSCs $O$ hPD-MSCs

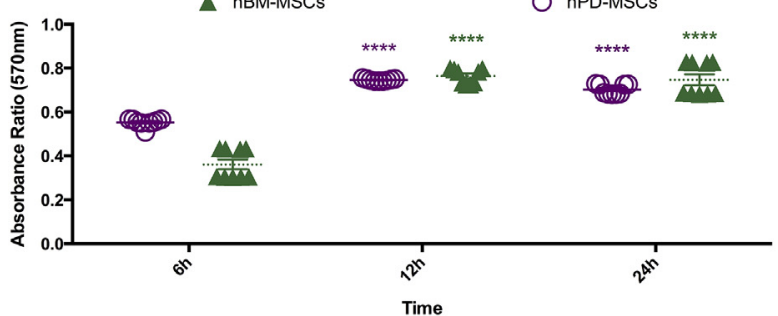

Cell Proliferation (50mM Glucose)

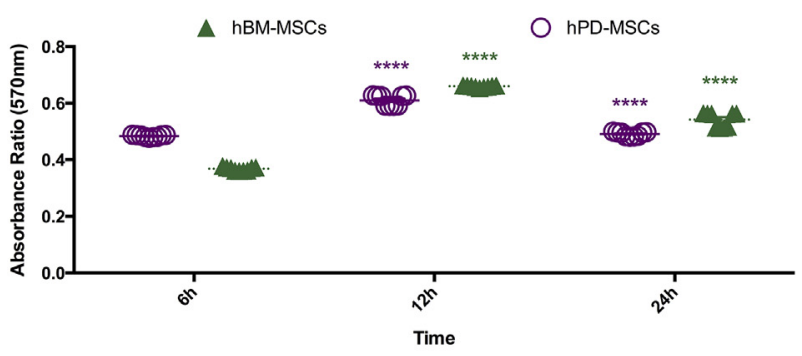

Cell Proliferation $\left(400 \mu \mathrm{M} \mathrm{CoCl}_{2}\right)$

hBM-MSCs

hPD-MSCs

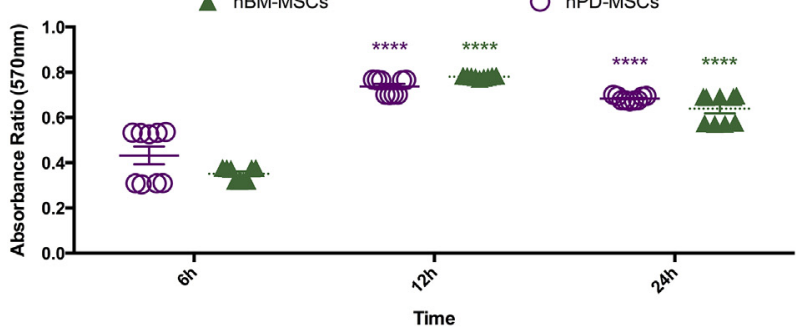

FIGURE E2. Cellular proliferation assays conducted at optimized concentrations for SDF- $1 \alpha(100 \mathrm{ng} / \mathrm{mL}), \mathrm{CoCl}_{2}(400 \mu \mathrm{M})$, and glucose $(50 \mathrm{mM})$. Bars represent means $\pm \mathrm{SD}$ of 3 independent experiments performed in triplicates. $S D F-1 \alpha$, Stromal-derived factor-1 alpha; hBM-MSCs, human bone marrow-derived mesenchymal stem cells; hPD-MSCs, human placenta-derived mesenchymal stem cells; $\mathrm{CoCl}_{2}$, cobalt chloride. 

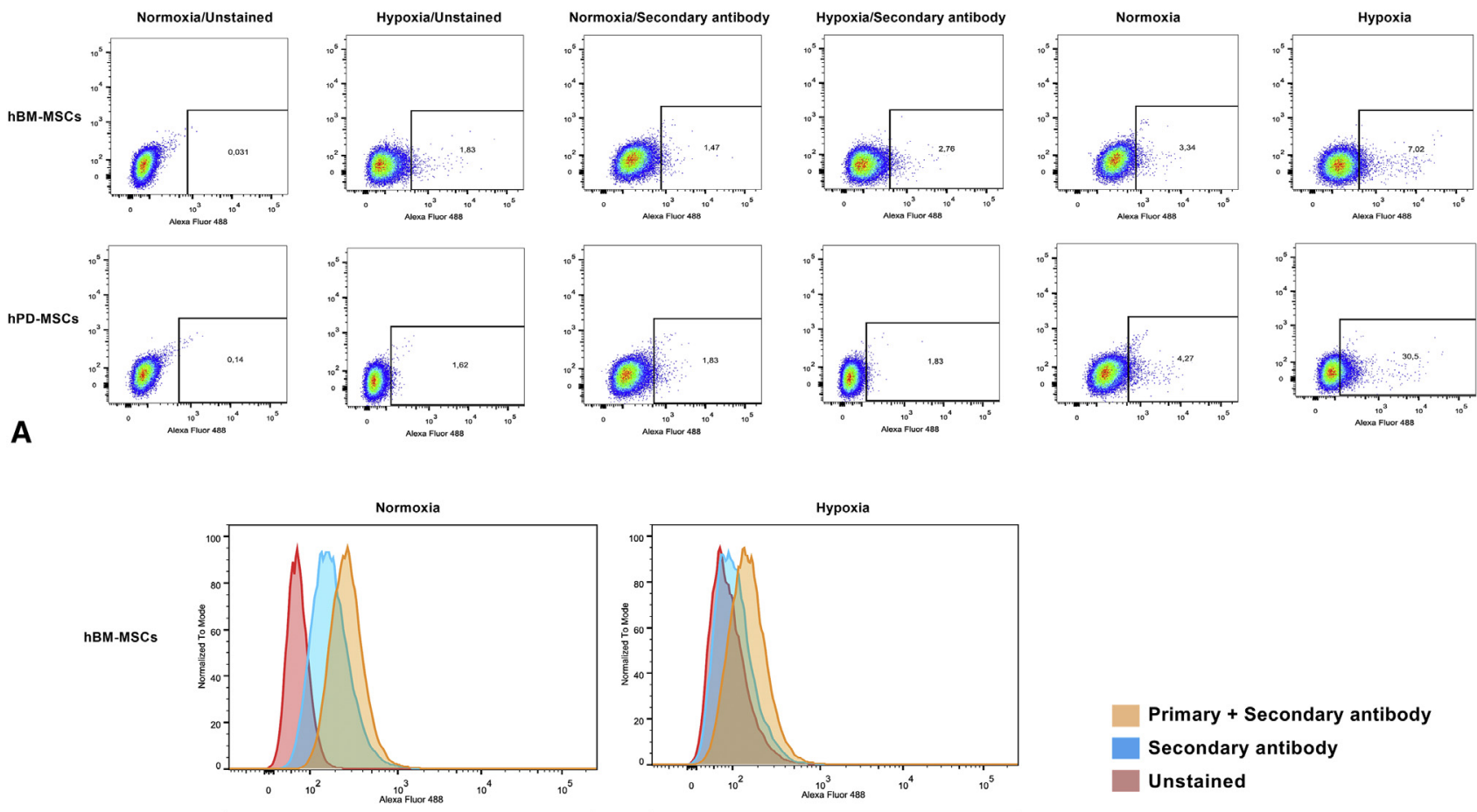

\author{
Primary + Secondary antibody \\ Secondary antibody \\ Unstained
}

B
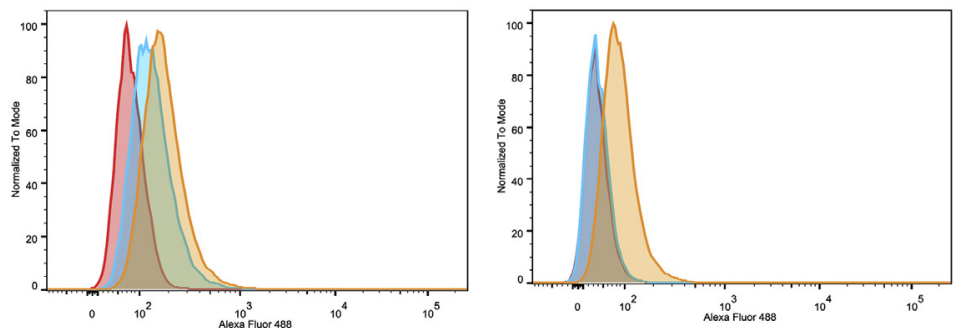

FIGURE E3. A, Sorting of CXCR4 ${ }^{+}$cells after the treatment with different conditions: normoxia, hypoxia, stained, and unstained with Alexa Fluor 488. $\mathrm{B}$, Shift of $\mathrm{CXCR}^{+}$cell population after treatment with different conditions in normoxia and hypoxia. hBM-MSCs, Human bone marrow-derived mesenchymal stem cells; $h P D-M S C s$, human placenta-derived mesenchymal stem cells.

TABLE E1. CXCR4 expression in response to SDF1- $\alpha$, glucose, and $\mathrm{CoCl}_{2}$ treatment $(\beta$-actin normalized)

\begin{tabular}{|c|c|c|c|}
\hline & & hBM-MSCs $(n=3)$ & hPD-MSCs $(n=3)$ \\
\hline Trea & & Mean \pm SD & Mean \pm SD \\
\hline SDF- $1 \alpha$ & - & $1.00 \pm 0$ & $1.13 \pm 0.0800$ \\
\hline SDF- $1 \alpha$ & + & $1.03 \pm 0.0700$ & $1.41 \pm 0.0346$ \\
\hline Glucose & - & $1.00 \pm 0$ & $1.05 \pm 0.0361$ \\
\hline Glucose & + & $1.02 \pm 0.0681$ & $1.15 \pm 0.0351$ \\
\hline $\mathrm{CoCl}_{2}$ & - & $1.00 \pm 0$ & $0.95 \pm 0.0808$ \\
\hline $\mathrm{CoCl}_{2}$ & + & $1.21 \pm 0.0123$ & $1.65 \pm 0.0473$ \\
\hline
\end{tabular}

hBM-MSCs, Human bone marrow-derived mesenchymal stem cells; hPD-MSCs, human placenta-derived mesenchymal stem cells; $S D$, standard deviation; $S D F-1 \alpha$, stromal-derived factor-1 alpha; $\mathrm{CoCl}_{2}$, cobalt chloride.

TABLE E2. FACS analysis of $\mathrm{CXCR4}^{+} \mathrm{MSCs}$ in $\mathrm{CoCl}_{2}$-induced hypoxia

\begin{tabular}{|c|c|c|c|}
\hline & & hBM-MSCs $(\mathbf{n}=\mathbf{3})$ & hPD-MSCs $(n=3)$ \\
\hline & & Mean \pm SD & Mean \pm SD \\
\hline $\mathrm{CoCl}_{2}$ & - & $3.00 \pm 0.3265$ & $3.79 \pm 0.4751$ \\
\hline $\mathrm{CoCl}_{2}$ & + & $7.50 \pm 0.4752$ & $31.75 \pm 1.2451$ \\
\hline
\end{tabular}

hBM-MSCs, Human bone marrow-derived mesenchymal stem cells; $h P D-M S C s$, human placenta-derived mesenchymal stem cells; $S D$, standard deviation; $\mathrm{CoCl}_{2}$, cobalt chloride. 
TABLE E3. Akt, ERK, and IL-6 expression in MSCs exposed to $\mathrm{CoCl}_{2}$-induced hypoxia

\begin{tabular}{|c|c|c|c|c|c|c|c|}
\hline & & \multicolumn{2}{|c|}{ p-Akt/Akt ratio } & \multicolumn{2}{|c|}{$(\mathrm{p}-\mathrm{ERK} 1 / 2) /(\mathrm{ERK} 1 / 2)$ ratio } & \multicolumn{2}{|c|}{ IL-6 } \\
\hline & & hBM-MSCs $(n=3)$ & hPD-MSCs $(n=3)$ & hBM-MSCs $(n=3)$ & $\overline{\text { hPD-MSCs }(n=3)}$ & hBM-MSCs $(n=3)$ & $\overline{\text { hPD-MSCs }(\mathrm{n}=3)}$ \\
\hline \multicolumn{2}{|c|}{ Treatment } & Mean \pm SD & Mean \pm SD & Mean \pm SD & Mean \pm SD & Mean \pm SD & Mean \pm SD \\
\hline $\mathrm{CoCl}_{2}$ & - & $1.00 \pm 0$ & $1.64 \pm 0.4035$ & $1.00 \pm 0$ & $0.92 \pm 0.0237$ & $1.00 \pm 0$ & $1.06 \pm 0.0286$ \\
\hline $\mathrm{CoCl}_{2}$ & + & $3.53 \pm 0.2486$ & $3.09 \pm 0.5242$ & $0.97 \pm 0.0095$ & $1.12 \pm 0.0240$ & $0.87 \pm 0.0226$ & $0.67 \pm 0.0361$ \\
\hline
\end{tabular}

p-Akt, Phosphorylated Akt; $A k t$, protein kinase B; $p$-ERK, phosphorylated ERK; ERK, extracellular signal-regulated kinase; IL-6, interleukin-6; $h B M-M S C s$, human bone marrowderived mesenchymal stem cells; $h P D-M S C s$, human placenta-derived mesenchymal stem cells; $S D$, standard deviation; $\mathrm{CoCl}_{2}$, cobalt chloride. 